\title{
Zentralnervöse Manifestation des Sharp-Syndroms als Ursache einer zerebellären Ataxie mit Gewichtsverlust
}

\author{
F. Herbst ${ }^{1}$, A. Artlich², G. Neuhäuser ${ }^{1}$, L. Gortner ${ }^{2}$, M. Diehl' ${ }^{3}$, J. Risse ${ }^{3}$ \\ ${ }^{1}$ Zentrum für Kinderheilkunde und Jugendmedizin, Abt. Neuropädiatrie, Justus-Liebig-Universität, Gießen \\ 2 Zentrum für Kinderheilkunde und Jugendmedizin, Abt. Allgemeinpädiatrie, JLU Gießen \\ ${ }^{3}$ Klinik für Nuklearmedizin, Johann Wolfgang Goethe-Universität, Frankfurt am Main
}

\section{Zusammenfassung}

Die zentralnervöse Manifestation einer Mischkollagenose (Sharp-Syndrom) ist eine Rarität. Die Diagnose wird durch den Nachweis von antinukleären Antikörpern der Gruppe U1-n-RNP in Serum und Liquor mit einem gesprenkelten Fluoreszenzmuster gesichert.

MCTD in the differential diagnosis of cerebellar ataxia

Mixed connective tissue disease is a rare disorder in childhood and seldom affects the CNS. The detection of U1-n-RNP antibodies in blood and CSF as well as speckled immunofluorescence pattern are diagnostic.

\section{Fallbericht}

Anamnese: Ein $11^{5} / 12$ Jahre altes philippinisches Mädchen erkrankte mit Gewichtsabnahme, Appetitlosigkeit, Bauchschmerzen sowie einer Raynaud-Symptomatik. 6 Monate zuvor wurde sie wegen zunehmender Muskelschwäche, Schwellungen in beiden Ellenbogengelenken, zervikaler Lymphadenopathie sowie Fieber untersucht. Eine ausführliche Diagnostik (Billdgebung, Entzündungs-, Rheuma- und Infektionszeichen) ergab bei nicht beschleunigter BSG lediglich einen leicht erhöhten ANA-Titer im Serum. In den folgenden 1,5 Monaten nahm sie $6 \mathrm{~kg}$ ab.

Untersuchungsbefund: Deutlich reduzierter Allgemein- und Ernährungszustand, Gewicht $23 \mathrm{~kg}(2,5 \mathrm{~kg}<\mathrm{P} 3)$, Länge $139 \mathrm{~cm}$ ( $1 \mathrm{~cm}<\mathrm{P} 3)$, Temperatur $38,2^{\circ} \mathrm{C}$. HNO-Bereich, Cor, Pulmo und Abdomen unauffällig, RR 100/80 mmHg. Breitbeiniger, unsicherer Gang. Standunsicherheit, Pronation der linken Hand beim Vorstrecken. Im Unterberger Tretversuch Abweichen nach links. Dysdiadochokinese links, deutlicher Intentionstremor, Sensibilität der linken Hand im Bereich von DIII-V nahezu aufgehoben. Segmentale Sensibilitätsstörungen der linken Körperhälfte. Allgemeine Verschmächtigung der Muskulatur, Wadenmuskeln schmerzhaft. Grobe Kraft der linken Extremitäten, armbetont deutlich gemindert, der linke Arm kann gegen Widerstand kaum gebeugt werden. Parästhesien im linken Bein und Arm, gelegentlich auch im rechten Bein. PSR und ASR nicht auslösbar, BSR, TSR, RPR rechts schwach, links nicht auslösbar, Pyramidenbahnzeichen negativ.

Laborbefunde: Pathologische Laborbefunde siehe Tab. 1. Im peripheren Blut Normwerte für rotes, weißes und Differenzialblutbild, Gerinnung, Elektrolyte, Transaminasen, Kreatinin, Harnstoff, Cholesterin und Triglyceride, Schilddrüsenparameter, CRP, BSG, $\mathrm{LDH}, \mathrm{CK}, \mathrm{NH}$, Folsäure, Vitamin E, B6 und B12, C3, C4, Laktat, Pyruvat, Kupfer, Blei, Quecksilber, sowie Gesamtkarnitin und überlangkettige Fettsäuren, Gliadin-Antikörper, ANCA, Hepatitis A, B, und C-, HIV-, CMV- und HTLV-Serologie.

Im Liquor Normwerte für Aminosäuren, Laktat, Glukose, Zellzahl, ologoklonale Banden und Neurotransmitter.

Weitere Diagnostik: Unauffällig waren Magen-Darm-Passage, Abdomensonographie, Röntgen Thorax und Mediastinum, Doppler der Abdominalgefäße, CCT, MRT HWS und BWS, EEG, EMG, NLG, augenärztliches Konsil, kinder-und jugendpsychiatrisches Konsil.
Tab. 1 Pathologische Laborwerte

\begin{tabular}{|lll|}
\hline Labor & Werte & Normbereich \\
\hline im Serum & & \\
IgA & $3,4 \mathrm{~g} / \mathrm{l}$ & $0,5-2,8 \mathrm{~g} / \mathrm{l}$ \\
IgM & $2,2 \mathrm{~g} / \mathrm{l}$ & $0,4-1,2 \mathrm{~g} / \mathrm{l}$ \\
Vit. B1 & 1,23 & $<1,1$ \\
ANA & $>1: 640$ & $<1: 80$ \\
im Liquor & & \\
Eiweiß & $1088 \mathrm{mg} / \mathrm{l}$ & $<500 \mathrm{mg} / \mathrm{l}$ \\
IgG-ANA & $1: 16$ mit gesprenkeltem & \\
& Fluoreszenzmuster & $<25 \mathrm{U} / \mathrm{l}$ \\
U1-n-RNP(U1/snRNP) & $136 \mathrm{U} / \mathrm{l}$ &
\end{tabular}

PET mit pathologisch vermindertem Glukosestoffwechsel bds. temporal und zerebellär (Abb. 1).

Verlauf: Das klinische Bild mit zerebellärer Ataxie ist durch den pathologisch veränderten zerebellären Glukosestoffwechsel erklärt. Für die ausgeprägte fokal betonte Muskelschwäche fand

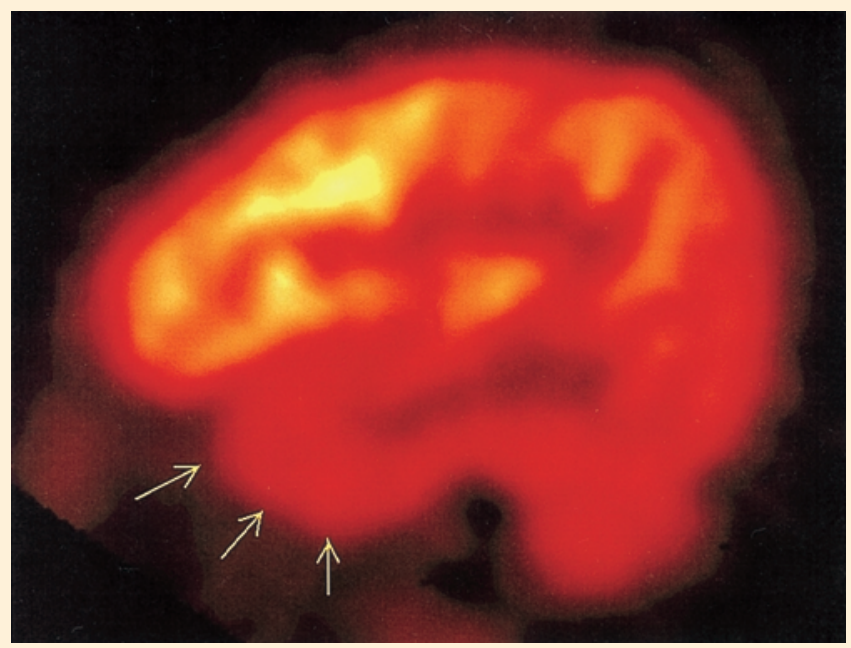

Abb.1 Pathologisch verminderter Glukosestoffwechsel temporal und zerebellär in der PET 
sich kein neuroanatomisches Korrelat. Unter teilparenteraler und hochkalorischer Ernährung besserten sich langsam Kachexie und Muskelschwäche. Zusätzlich erhielt sie Prednisolon und intensiv Physiotherapie. Nachdem spezifische antinukleäre Antikörper im Liquor gefunden wurden, gaben wir über einen Zeitraum von drei Tagen hochdosiert Prednisolon als Stoßtherapie. Der klinische Zustand besserte sich schnell, die neurologischen Zeichen nahmen allmählich ab.

Nach der Entlassung zeigten sich keine wesentlichen Fortschritte, so dass die Patientin derzeit alle 4 Wochen stationär eine 3-tägige Kortison-Stoßtherapie erhält, worunter sie derzeit ohne Unterstützung laufen kann, jedoch weiterhin ein ataktisches Gangbild zeigt.

Diagnose: Zentralnervöse Manifestation des Sharp-Syndroms.

\section{Kommentar}

Das Sharp-Syndrom wird auch als „Mischkollagenose“ bzw. „mixed connective tissue disease“ (MCTD) bezeichnet [4]. Bei Kindern sind seit 1996224 Fälle mitgeteilt [1]. Die häufigsten Manifestationen sind Arthritiden (besonders die kleinen Fingergelenke), Raynaud-Symptomatik, Myositis und entzündliche Hautveränderungen (Dermatomyositis), sowie Organbeteiligung wie Pneumonie, pulmonale Hypertension, Perikarditis und Myokarditis, Vaskulitis, ösophageale Motilitätsstörung, Nephropathie, Neuropathie und Enzephalitis. Charakteristisch sind U1nRNP-Antikörper im Serum, allein jedoch noch nicht beweisend für ein „MCTD“. Erst das zusätzliche Auftreten eines gesprenkelten Fluoreszenz-Musters („speckled type“) sichert die Diagnose [4]. Eine ZNS- Manifestation des Sharp-Syndroms ist im Kindesalter extrem selten und wurde erstmals 1993 von Graf et al. [2] beschrieben. Eine Vaskulitis (im Extremfall mit fibrinöser Nekrose zerebraler Gefäße) wird für die neurologischen Symptome verantwortlich gemacht [2]. Diagnostisch ist neben spezifischen Antikörpern, Erhöhung von Eiweiß, Interleukin-6 sowie mononukleäre Zellen im Liquor auch die PET hilfreich, die zerebrale oder zerebelläre Hypoperfusionen zeigt [3]. Die neurologischen Symptome bilden sich unter Therapie nur sehr langsam, nicht immer vollständig zurück.

\section{Danksagung}

Wir danken Herrn Dr. med. B. Wilken, Göttingen, sowie Frau PD Dr. med. M. Schöntube, Berlin, für freundliche und prompte Unterstützung.

\section{Literatur}

${ }^{1}$ Michels $\mathrm{H}$. Course of mixed connective tissue disease in children. Ann Med 1997; 29: 359-364

${ }^{2}$ Graf WD, Milstein JM, Sherry DD. Stroke and mixed connective tissue disease. J Child Neurol 1993; 8: 256-259

${ }^{3}$ Kuroki M, Okayama A, Kuwata G, Okamoto M, Tanaka G, Iga M, Kai $\mathrm{Y}$, Matsuyam M, Murai K, Tsubouchi $\mathrm{H}$. A case of mixed connective tissue disease with lupus-like manifestations of the central nervous system, successfully treated with cyclophosphamide combined with prednisolone. Ryumachi 2000; 40: 627-632

${ }^{4}$ Rosenthal M. Juvenile Sharp syndrome. Helv Paediatr Acta 1978 Aug; 33: $251-258$

\section{F. Herbst}

Zentrum f. Kinderheilkunde

Abt. Neuropädiatrie

Justus-Liebig-Universität

Feulgenstr. 12

35392 Gießen 